acceptable to many people who would otherwise be reluctant to seek psychiatric help. The treatment programmes are a combination of traditional clinical methods and behaviour modification techniques or stress management skills, treating not just the presenting condition but the whole person.

Physiotherapists are also licensed to touch their patients. Touch evokes trust and caring. A neck and shoulder or back massage can produce deep relaxation and a sense of well being in the patient. Sharing problems with an active listener who is not there to give advice, but may occasionally direct the line of thinking so that the patient sees things for himself in a clearer light and forms his own solutions to his problems, can be the unlooked for bonus of a treatment session.

The patient who benefits most from a physiotherapeutic approach is the one with persistent symptoms that have devastatingly reduced his quality of life and for which no physical cause can be found. To be told, after lengthy investigations with a variety of consultants, that the problem is all "in the mind" is upsetting; to be summarily dismissed by a neurologist or an orthopaedic consultant and referred to a psychiatrist is the ultimate insult. Such patients finding themselves in a physiotherapy department, probably not for the first time, will naturally be sceptical. The key to a successful resolution lies in the approach to the problem. The focus of attention will be the quality of life. The patient identifies the areas of his life that he is dissatisfied with and wants to change. These are placed in order of priority and then worked at in small steps. This could include an exercise regime, learning stress management skills including relaxation, and planned graded activities. The reward and the motivation to continue what may be a long uphill struggle is the patient's recognition of his achievements. The therapist does not hide the fact that the patient should expect to work hard, and it will be painful and that there may be relapses. Ultimately the patient has a choice. He can improve the quality of his life in spite of his symptoms, or he can continue his search for a diagnosis that would absolve him from any responsibility for his condition. Experience has shown me that those who choose the former are grateful not only to be released from the prison of their pain but also for a therapeutic relationship that allows them to maintain their dignity. The therapist is the catalyst to a successful outcome and not the crutch that the patient learns to lean on.

There is also a role for the physiotherapist in the treatment of disorders such as anorexia nervosa that have a body image component. Using the non-verbal skills of massage, relaxation and movement, it is possible to facilitate an internal as well as an external feeling of self awareness. This, combined with practical stress management coping skills, induces a greater sense of acceptance and understanding of the body while the patient is undergoing a treatment package of weight restoration followed by psychotherapy. It will be appreciated that this is a perhaps surprisingly subtle way of applying generic physiotherapy skills to a specific condition. It is a far cry from the "jolly hockey sticks" approach for which we are sometimes known and which has a very limited role in psychiatry.

Physiotherapists working on multidisciplinary substance abuse rehabilitation teams, encourage their clients to be actively involved in their own physical rehabilitation. They organise circuit training sessions and take and direct clients to leisure activities. They take an active counselling role in health education and stress management programmes. As these clients tend to be "head" orientated people who blot out their problems and anxieties by eliminating them or dulling them through the abuse of alcohol or drugs, the awareness of a body that feels stiff after exercise, helps bring them in touch with their whole self. So exercise has the dual function of improving fitness and integrating head and body into a whole person.

It would not be right to conclude without mentioning the valuable work that we do with the elderly, working alongside the nurses to maintain patients' functional mobility and independence; or with the long-stay in- and out-patients whose smoke-abused chests and poor posture we endeavour to improve.

So I would agree with Professor Cawley that "properly arranged team work is a powerful way of helping the mentally disordered person, it is a most profitable modus operandi for the workers, and it is absolutely necessary for the satisfactory education of psychiatrists". I would also make a special plea that psychiatrists in the course of their training learn how the skills of the physiotherapist can benefit their patients.

Supt Physiotherapist, Mental Health Unit Coney Hill Hospital, Gloucester GL4 7QJ

\section{Abuse of mentally handicapped adults}

\section{DeAR Sirs}

I read with much interest and relief the article on 'Abuse of Mentally Handicapped Adults' by Leila Cooke (Psychiatric Bulletin, October 1990, 14, 608-609). It is an issue that has only recently been acknowledged by those working in the field, and yet we know from our own clinical experience that this aspect of 'care' has been a silent one. Little research has been done in this difficult area, but we do have pointers to its prevalence, knowing the heightened vulnerability of our patient/client group.

In my own clinical practice I know of mentally handicapped adults who have been sexually abused in 
the distant past and who are only now seeking permission to talk about it. There is also an increasing number of adults who present with a history of recent abuse or, more worrying, who present with symptoms indicative of current abuse. In those who are nonverbal or who have limited communicative skills, management decisions often have to be made on these symptoms alone without knowing who the perpetrator is. To complicate matters, many 'problem behaviours' are often, rightly or wrongly, accepted as an intrinsic part of mental handicap, e.g. enuresis, rocking, compulsive public masturbation (Brown \& Craft, 1989).

At present it is difficult to know how to begin to manage such a case. There is, understandably, hesitation at calling for police involvement, but in my experience of two cases, one recent and one on-going, the police have been extremely helpful (O'Hara, 1989). How we protect an adult with mental handicap after abuse is suspected is an enormous problem, and I would very much support Dr Cooke's suggestion of an amendment to the 1983 Mental Health Act to enable guardianship to be used for such purposes.

On a slightly different point, it appears that the practice of 'sexual abuse' is the norm in large institutions for the mentally handicapped. By that, I mean that staff have often turned a blind eye to the sexual encounters of mentally handicapped residents of all abilities. To some extent, although many will have an intelligence quotient below 50 (and therefore considered incapable of giving consent), most are able to express an acceptance or rejection of sexual advances in their own limited way. This practice has not caused much of a problem until now. With the more able residents being discharged into small community homes, and a core of more dependent residents being left within the hospital, we are now in a position where ex-residents are visiting, explicitly to have sex with those remaining, outside of an actual relationship. Quite clearly our residents are being taken advantage of, and while there is often no resistance on their part, possibly because they are used to being treated in this way and enjoy the experience, not knowing any other form of affection or appreciation, professionals working in this field will need to be aware of this problem and the dilemma it poses. There should be a locally agreed policy for dealing with this problem, as well as abuse in general.

Department of Psychological Medicine

JEAN O'HARA

St Bartholomew's Hospital

London ECIA $7 B E$

\section{References}

Brown, H. \& Craft, A. (eds) (1989) Thinking the Unthinkable: Papers on Sexual Abuse and People with Learning Difficulties. FPA Education Unit.
COOKE, L. B. (1990) Abuse of mentally handicapped adults. Psychiatric Bulletin, 14, 608-609.

O'HARA, J. (1989) Pregnancy in a severely mentally handicapped adult. Journal of Medical Ethics, 15, 197-199.

Dear Sirs

We were interested to read the paper by Dr Leila B. Cooke (Psychiatric Bulletin, October 1990, 14, 608-609) concerning the possible high rate of abuse of mentally handicapped adults. Should this be proven, the abuse of mentally handicapped adults would be of serious concern to us all.

However, we feel that this situation is not currently proven. The methodology employed by Dr Cooke can be seriously faulted. She describes having circulated a questionnaire to 38 "representative" consultants in the psychiatry of mental handicap, of whom $63 \%$ returned the questionnaire. It is likely that the consultants to whom she sent the questionnaire represent a considerably biased sample. Additionally, she stated that she had received ten unsolicited questionnaires and she included these in her sample of respondents. It would seem inconceivable that such unsolicited questionnaires were unbiased.

The estimates of prevalence of abuse (and there must be uncertainty of its precise definition) range from between $0.2 \%-20 \%$. An estimate with a range of a factor of 100-fold can be little more than impressionistic.

We believe that a proper study of the evidence for and true prevalence of abuse of the mentally handicapped is urgently called for. However, we do not believe that this study with its serious methodological faults should enter the canon of mental handicap psychiatry.

\section{R. A. Collacott} S. A. COOPER

Leicester Frith Hospital

LeicesterLE3 9QF

\section{DeAR SIRS}

I am pleased to have the opportunity to respond to the criticisms of my paper cited in the letter from Drs Collacott \& Cooper. I would refute the suggestion that the consultants contacted were likely to be a biased sample. As stated in the paper, these consultants had been elected by their peers throughout the United Kingdom to represent them at College or regional level. In addition, they all have large clinical practices and their experience of abuse is likely to be the same as that of any other consultant working in the field of psychiatry of mental handicap.

Estimates of prevalence can only be based on information currently available. I would point out that this was a preliminary survey only, intended to highlight the problem, and not a controlled trial. I agree that further studies are urgently needed in order to elucidate this serious matter-perhaps Drs 